УДК 341

DOI

\author{
Нигяр И. Мамедова \\ orcid.org/0000-0003-4676-7883 \\ докторант кафедры международного частного права и европейского права \\ Бакинского государственного университета
}

\title{
ОСОБЕННОСТИ ПРАВОВОГО РЕГУЛИРОВАНИЯ МЕЖДУНАРОДНОЙ ЗАЩИТЫ ПАТЕНТНЫХ ПРАВ
}

Актуальность темы исследования обусловлена тем, что на международном уровне не выработана однозначная и единая для всех стран позиция защиты патентных прав. В связи с этим возникает множество задач, требующих своего решения, поскольку законодательства различных стран не всегда успевают за бурным прогрессом в этой области. Международно-правовая защита патентных прав, будучи институтом международного интеллектуального права, входит в систему международного частного права. С точки зрения правовой природы, такой институт имеет комплексный характер. Комплексный характер в первую очередь вытекает из своеобразных особенностей патентных прав. Комплексность названого правового регулирования выражается также в параллельном использовании материальных, процессуальных и коллизионных норм международного и национального права.

Степень научной разработанности проблемы. В современный период в отечественной юридической науке практически отсутствуют комплексные исследования, касающиеся международно-правовой защиты патентных прав. Специальные диссертационные и монографические исследования по теме исследования не проводились. Имеющиеся в области научные работы были посвящены рассмотрению частных вопросов правового регулирования промышленной собственности в законодательстве (Керимов Г.Г. «Правовая охрана объектов промышленной собственности в международном частном праве»; НАН Азерб., Ин-т Философии и Политико-Правовых Исследований. Баку, 2007. 196 с.)

Цель работы заключается в определении специфики международно-правовой защиты патентных прав. Как видим, вопрос защиты патентных прав в иностранных государствах является достаточно сложным и затратным. Но международные организации стремятся к упрощению процедуры получения патента и унификации норм в этой сфеpe.

Изложение основного материала. Развитие инновационной деятельности возможно только на основе эффективной нормативно-правовой базы по охране интеллектуальной собственности, так как только надежная правовая защищенность результатов научно-технического труда способна обеспечить максимальное соблюдение интересов авторов изобретений, патентообладателей и общенациональных интересов государства.

Важный момент в регулировании отношений, связанных с международно-правовой защитой патентных прав, состоит в создании гарантий того, что объект патента не будет использован без разрешения автора патента или патентообладателя. Правовое регулирование международной защиты патентных прав в направлении создания такой гарантии обуславливается особенностями, которыми обладают права. Исходя из отмеченных свойств, можно прийти к такому предварительному заключению, что:

1) регулирование международно-правовой защиты патентных прав имеет комплексный характер, то есть сочетает в себе признаки конституционного, гражданского, административного, уголовного правового и прочего регулирования;

2) также основываясь на положении «подтверждая, что права интеллектуальной собственности являются правами отдельных лиц», закрепленном в преамбуле «Соглашения по торговым аспектам прав интеллектуальной собственности» (далее - ТРИПС) [37], патентные права входят в систему частных (гражданских) прав. В этом смысле правовое регулирование, связанное с правами, осуществляется в рамках сферы интеллектуального права, относящегося к системе частного права, где материальную основу регулирования составляют, как правило, отношения личного и имущественного характера, возникающие в связи с осуществлением патентных прав;

3) несмотря на то, что целью является защита патентных прав частного характера, процесс защиты и используемые правовые средства могут иметь публично-правовой характер. Идентичность цели обуславливает их единство.

С точки зрения объекта исследования нас интересует международное правовое регулирование патентных прав. Заранее надо отметить, что вышеизложенное, относящееся к правовому регулированию защиты патентных прав, также относится и к международно-правовой защите. В качестве дополнительного свойства, обуславливающего комплексность регулирования, связанного с последним, необходимо отметить только согласование международного права с национальным 
правовым регулированием. Так, международное правовое регулирование патентных прав, соответственно, наряду с наличием необходимых для этого процессуальных форм также обуславливает взаимосвязь форм международной и внутригосударственной защиты.

В юридической литературе определенные споры вызывает вопрос, к какой отрасли права должна быть отнесена международно-правовая защита патентных прав как институт. Можно встретить мнения, относящие право интеллектуальной собственности к международному публичному праву, сделав право на защиту интеллектуальных прав частных лиц задачей государства по обеспечению такой защиты, к международному экономическому праву, в частности, в рамках международных вещных прав [5, с. 337-339] или под названием международного права на интеллектуальную собственность [15, с. 479-481].

Международно-правовая защита патентных прав, будучи объектом регулирования, входит в сферу регулирования международного патентного права. Международное патентное право, являясь отраслью международного интеллектуального права и, следовательно, подотраслью международного частного права, сочетает в себе нормы внутригосударственного законодательства и международного договора, устанавливающие правовой режим промышленной собственности с иностранным элементом [26; 27$]$.

C последним мнением можно полностью согласиться. Свою позицию дополнительно можем объяснить также следующими факторами. Bo-nервых, так как патентные права имеют территориальный характер, обеспечить их международно-правовую защиту лишь национальным правом невозможно. Так как отношения, связанные с международно-правовой защитой патентных прав, возникают не между государствами, такая защита не может быть обеспечена в рамках международного публичного права, так как международное публичное право регулирует только межгосударственные отношения. А международное частное право, обладая своеобразным предметом регулирования, будучи самостоятельным правовым институтом, не входит в рамки ни национального, ни международного публичного права [10, с. 33]. В этом смысле нельзя соглашаться с подходами, рассматривающими международное частное право как подотрасль гражданского права [1, с. 13] или как специальную, независимую отрасль [12; 13], регулирующую гражданские правоотношения в широком смысле.

Bo-вторых, предмет регулирования частного права составляют отношения, связанные с правопорядком двух и более государств, возникающие между частными лицами по реализации имущественных и личных неимущественных прав
[8, с. 21-22]. Международное частноправовое регулирование, включая защиту личных прав как прав человека осуществляет это в своеобразной форме. Как отмечал M.M. Богуславский, «защита прав человека является одной из основных задач международного частного права» [3, с. 21]. Так, в международном частном праве обеспечивается защита патентных прав не какого-либо человека, а именно иностранцев как частных субъектов. Международное частное право подразумевает признание субъективных прав, приобретенных за границей.

B-mретьих, международное частное право регулирует отношения, связанные с реализацией частных прав и интересов субъектов права. А такие отношения могут возникнуть как в сфере частных прав и интересов, так и в связи с их защитой [24, с. 19]. Опираясь на это мнение и основываясь на ТРИПС, закрепившему в своей преамбуле «права интеллектуальной собственности как права отдельных лиц», можно отметить два момента:

1) международно-правовую защиту патентных прав целесообразнее осуществлять именно в рамках международного частного права;

2) в качестве объекта международного частноправового регулирования в узком смысле выступают не гражданские правоотношения, а любые правоотношения специального характера (в том числе интеллектуальные правоотношения).

Защита частных прав осуществляется в определенных процессуальных формах [24, с. 19]. Эти формы реализуются в рамках международного гражданского процесса. Регулирование международно-правовой защиты патентных прав именно в рамках международного частного права также логично по той причине, что последний как система включает также международный гражданский процесс. Хоть в правовой литературе отношение к этому вопросу и неоднозначное, необходимо учитывать, что существующий в частных отношениях «иностранный элемент» порождает определенные процессуальные последствия [23, с. 84]. Регулирование защиты частных прав, входящих в такие последствия, в конкретном случае - патентных прав, вне международного частного права нелогично. В этом смысле средства, используемые в процессе защиты таких прав, хоть и имеют публично-правовой характер, преследуемая ими цель - частноправовая. То есть как международное частное право, так и международный гражданский процесс служит единой цели - защите прав и интересов участников международного гражданского оборота [9, с. 27].

Значительность осуществления защиты патентных прав в рамках международного частного права также можно объяснять тем, что в пределах этих рамок предоставляется возможность пользоваться негосударственным регулированием. Известно, что правовую основу такого регулирования 
составляют, как правило, международные, в том числе установленные неправительственными организациями, правила рекомендательного характера, которые по природе являются soft law. Не исключено принятие таких правил в рамках Всемирной организации интеллектуальной собственности (далее - ВОИС) и Всемирной торговой организации (далее - ВТО), в том числе Ассоциации международного права. Проекты принципов коллизионного права и международной юрисдикции в сфере интеллектуальных прав (принципы ALI - 2007 г.; принципы WASEDA; принципы Transparent [13, с. 16]) можно отнести к такого рода правилам.

Одной из основных особенностей, которыми обладает международное частное право, является регулирование им отношений, связанных с правовой системой нескольких государств [19, с. 86]. Некоторые авторы обращают внимание на то, что такая связь существует не с правовой системой (здесь правовая система принимается как система правовых норм - H. M.), а с правопорядком или юрисдикцией государств в целом [2, с. 62 ; 8, с. 21-22]. Учитывая закрепление в законодательстве государств (например, Грузии 1998 г.; Туниса - 1998 г. и так далее) этого свойства и соглашаясь с отмеченным мнением, необходимо акцентировать, что связь с правопорядком нескольких государств в конечном итоге обуславливаетвыборкомпетентногоправопорядкадля возникновения правовой коллизии и регулирования существующего отношения.

Вопрос вызывает то, в каком направлении влияет территориальный характер патентных прав на защиту таких прав. Суждения Л.А. Лунца относительно не возникновения вопроса коллизии в связи с территориальным характером, то есть проблемы того, правом какого государства устанавливаются субъективные права, в настоящее время поддерживаются в юридической литературе [11, с. 458-459]. Согласно такому подходу отсутствие у законодательства в связи с государственным патентом силы вне территориальности в конечном итоге исключает использование в регулировании отношений, связанных с международно-правовой защитой патентных прав, метода коллизионного регулирования. Так как право каждого государства самостоятельно устанавливает возникновение, прекращение, объем и защиту патентного права без отсылки к зарубежному праву, ни одно государство не может обеспечить охрану права интеллектуальной собственности с помощью своего внутреннего законодательства на территории другого государства [4, с. 15].

Но, как отмечал и Л.А. Лунц, заключение международных соглашений об обоюдном признании прав интеллектуальной собственности обуславливает признание субъективных исключительных прав и возникновение вопроса коллизии в такой сфере $[16$, с. 665]. Развитие права и судебной практики в последнее время также показывает, что для осуществления адекватной правовой защиты необходимо устранение территориального характера интеллектуальных прав. По нашему мнению, международное частное право, будучи комплексной регулятивной системой, объединяющей в себе международно-правовое и внутригосударственное правовое регулирование [18, с. 12], может эффективнее обеспечивать устранение территориального характера патентных прав и его международно-правовую защиту. При этом территориальный характер не является достаточным основанием для исключения использования метода коллизионно-правового регулирования и императивного применения lex loci protectionis в связи с защитой патентных прав. Применение коллизионной нормы, в конкретном случае lex loci protectionis, принято на международном уровне. Так, согласно ст. 60 Европейской Патентной Конвенции [36], если изобретатель является работником, право устанавливается законодательством государства основного места работы работника, а если установить его невозможно, применяется законодательство государства, где расположено предприятие работодателя. В ст. 8 Регламента № 864 «О праве, подлежащем применению к внедоговорным обязательствам» (далее - Рим II) [28], принятого Европейским Парламентом и Советом Евросоюза в 2007 г., предусмотрено применение к внедоговорному обязательству, возникающему вследствие нарушения права интеллектуальной собственности, права страны, применительно к которой предъявляется требование о защите (lex loci protectionis), а в п. 2 настоящей статьи в качестве исключения - права страны, где право нарушено (lex loci delicti). Помимо того, оговорка о применении национального режима в судебной практике многих государств (США, Германии, Франции и так далее) по применению ст. 5 Бернской Конвенции 1886 г. «Об охране литературных и художественных произведений» квалифицируется именно как коллизионная норма [14, с. 29].

В юридической литературе в целом отмечается использование в области охраны прав интеллектуальной собственности таких коллизионных принципов [7, с. 17]:

1) lex contractus;

2) lex fori и право страны охраны;

3) право страны происхождения (lex loci origins $-H . M$.);

4) lex loci delicti.

По мнению Г.Г. Керимова, проводившего сравнительный анализ международного частного правового законодательства государств, в коллизионном правовом регулировании, связанном с вопросами осуществления и нарушения 
патентных прав, различают два основных подхода. Согласно первому подходу, при выборе права в указанных вопросах преимущество дается праву государства, предоставляющего защиту (lex loci protectionis). Например, такой подход закреплен в законодательстве Бельгии, Швеции. При втором подходе (США, Австрия, Англия и так далее) преимущество за правом места наступления правонарушения (lex loci delicti) [12, с. 16]. Существует практика закрепления конкретных положений, касающихся коллизионного правового регулирования интеллектуальных прав, в законах о национальном международном частном праве, принятых в XXI веке. В этих законах, как правило, закрепляется коллизионный принцип lex loci protectionis. Например, Закон Бельгии «0 Кодексе международного частного права» 2004 г. (ст. 93) [29], Закон Украины «О международном частном праве» от 2005 г. (ст. 37) [30], Закон Турции «О международном частном праве и процессе» от 2007 г. (ст. 23) [31]. В отличие от них, согласно «Кодексу международного частного права» Болгарии, принятому в 2005 г. [32], в случае применения к возникновению, содержанию, передаче и прекращению прав промышленной собственности права государства, где выдан или зарегистрирован патент (ст. 71), обязательства, вытекающие из нарушения таких прав, регулируются правом государства, где предоставляется защита (lex loci protectionis) (ст. 110).

А что касается законодательства Азербайджанской Республики (далее - AP), необходимо учесть, что в Законе «О международном частном праве» от 2000 г. (далее - Закон о МЧП) [33] в целом не подразумевается норма, связанная с интеллектуальными правами. Это можно объяснить тем, что Закон о МЧП исходит из позиции узкого подхода, связанного с предметом международного частного права. То есть Закон о МЧП сочетает в себе коллизионные нормы, регулирующие гражданские правоотношения только в узком смысле [17, с. 113]. С этой точки зрения коллизионный принцип lex loci delicti, предусмотренный в ст. 26 Закона о МЧП для применения к обязательствам, возникающим впоследствии причинения ущерба, также можем применить к случаям причинения ущерба патентным правам. Причем в ст. 23 Закона о МЧП закреплено применение права места осуществления таких прав к неимущественным правам, их защите. Отмеченное положение также может распространиться только на личные патентные права. По нашему мнению, чтобы не допустить возникновения недоразумений, на практике АР можно применить два возможных варианта в направлении коллизионно-правового регулирования патентных прав:

1) de lege ferenda: включить в Закон о МЧП в целом положения, связанные с интеллектуальными правами, как в законодательстве многих государств (Швеции, Венгрии, Украины и так далее);

2) de lege lata: пользоваться положениями, имеющимися в Законе о МЧП (например, ст. ст. 23-26), в коллизионно-правовом регулировании международно-правовой защиты патентных прав.

Так, если принимать во внимание осуществление патентных прав на основе договора, здесь коллизионно-правовое регулирование может основываться на общих коллизионных принципах, характерных для договорных обязательств. В действительности в законодательстве вышеуказанных государств используется такой опыт. Например, в «Кодексе международного частного права» Болгарии (ст. 73) отмечается применение используемых в договорных обязательствах положений к договорам, предметом которых являются объекты интеллектуальной собственности (Х раздел). А это обуславливает использование свободы воли и принципов тесной связи в общей форме. Хотя в законодательстве некоторых государств указывается конкретное положение. Например, в Законе Швейцарии «О международном частном праве» от 1987 г. (ст. 122) [21] закреплено применение к договорам в сфере интеллектуальной собственности права места, где обычно находится сторона, передающая или предоставляющая права интеллектуальной собственности.

Относительно защиты патентных прав могут возникнуть коллизии в связи со следующими вопросами:

1) с кругом объектов патента;

2) с требованиями, распространяющимися на объекты патента;

3) с подачей заявки на патент [6, с. 41-43];

4) со сроком действия патентных прав;

5) с участием иностранного автора или патентообладателя в интеллектуальных правоотношениях;

6) с правовым статусом субъектов патентных прав;

7) с реализацией патентных прав.

Коллизия права в международном частном праве является возможностью применения к таким отношениям, обуславливающимся особенностью частных правоотношений с иностранным элементом и приводящим к возникновению различных последствий, решению существующего вопроса по-разному, частного права двух и более государства [22, с. 16].

Возникновение такой коллизии имеет две главные причины [24, с. 16]:

1) первая объективная причина состоит в том, что участвующий в отношениях иностранный элемент делает эти отношения связанными с правовой системой двух или более государств;

2) такие правовые системы, связанные с отношениями, отличаются по содержанию [9, с. 110]. 
Несмотря на то, что связь частного отношения с правовой системой двух или более государств является обязательным фактором в международном частноправовом регулировании, во всех случаях это не делает необходимым возникновение коллизии и решение такой коллизии выбором права (коллизия правовым методом - H. M.). Так, использование метода прямого (материально-правовое регулирование) правового регулирования устраняет проблему столкновения частноправовых норм государств, связанных с отношением, и не учитывает коллизионный этап - этап выбора права [24, с. 18]. В этом смысле обобщенные материально-правовые нормы, закрепленные в международных договорах, действующих в области патентных прав (например, положения «Парижской Конвенции по охране промышленной собственности» от 1883 г. [35] о принудительном лицензировании, ст. 5), регулируют международно-правовую защиту патентного права именно напрямую. В международном частноправовом законодательстве многих государств специально закреплено, что наличие обобщенных материально-правовых норм исключает определение применимого права на основании коллизионной нормы (Рим II, ст. 8; Гражданский кодекс Российской Федерации, ст. 1186; Закон Украины «О международном частном праве», ст. 4).

Какой коллизионно-правовой или материально-правовой метод должен быть использован в международном частноправовом регулировании, обуславливается особенностями объекта регулирования. С целью устранения территориального характера патентных прав, как правило, преимущество дается унифицированной форме материально-правового регулирования. Например, материально-правовые нормы, закрепленные в международных договорах в связи с установлением условий патентоспособности, случаями, когда использование патентных прав третьих лиц не является нарушением таких прав, сроком действия патентных прав и так далее, устраняет наступление коллизии между национальными правовыми системами, связанными с отмеченными вопросами. Но не все нормы, закрепленные в международных договорах в этой области, имеют материально-правовой характер. И поэтому не исключено ни использование коллизионной нормы, ни отсылка к законодательству того или другого государства для конкретизации предписания общего характера в порядке национального законодательства.

В действительности целью исследования с точки зрения предмета является международно-правовая защита патентных прав. Текущей целью, применимой для этой международной частноправовой нормы, является установление наиболее приемлемого права (lex beniqnitatis). В сфере международного частноправового регулирования такое право устанавливается по принципу тесной связи. Согласно тесной связи, являющейся особым принципом международного частного права, как при создании материально-правовых норм, так и при выборе компетентного права на основании коллизионной нормы преимущество дается правовой системе, наиболее тесно связанной с отношениями. Тесная связь выражает как территориальную, так и правовую связь отношения. Отношение через любой облагаемый им элемент может быть связано с территорией того или другого государства и правовой системой. Например, субъект отношения связан с территорией и правовой системой государства, к которому он принадлежит, по причине гражданства или проживания, государства, где расположен объект, а права и обязанности субъектов - с государством, где они осуществляются [25]. То есть территориальный характер присущ любому частноправовому отношению. Отмеченные элементы могут связать отношение с несколькими государствами и его правовой системой. При этом для регулирования отношения необходимо использовать тот элемент, который наиболее тесно связан с ним. Как отмечено в Риме II, если из обстоятельств дела явно следует, что дело связано с правом какого-либо другого государства более тесно, то в этом случае применяется не право, установленное согласно п. п. 1 и 2 такой статьи названого Регламента, а право наиболее тесно связанного государства в качестве исключения (ст. 4) [28].

Во многих случаях реализация частноправовых отношений обуславливает введение в оборот публично-правовых норм. А осуществление публично-правовых отношений обуславливает правовую связь отношения с таким государством [25]. Государственная регистрация патента для возникновения патентных прав, применение административных, налоговых, таможенных и гражданско-процессуальных правовых норм в направлении использования этих прав вытекает из названой правовой связи. Эта связь хоть и обуславливает преимущество использования правовой системы соответствующего государства в международно-правовой защите патентных прав, но не исключает такое:

1) «перемещение» идеи, составляющей объект патентного права, во времени и пространстве, выходя за границы соответствующего государства $[24$, c. 206];

2) применение публично-правовых норм, участвующих в реализации частного права соответствующего государства, в качестве иностранного права.

Последний фактор также закреплен в международном частноправовом законодательстве большинства стран (Швеции, Италии, Украины и так 
далее), в том числе в Законе о МЧП (ст. 1.4). Согласно закрепленным положениям, применение норм иностранного права не может быть ограничено только по той причине, что они имеют публично-правовой характер. Случай применения норм другого государства общего характера также может быть установлен международными договорами. Например, в двусторонних договорах о правовой помощи (Договор между АР и Болгарией от 1995 г., ст. 12; Договор между АР и Исламской Республикой Иран от 1998 г., ст. 8) отмечена возможность использования по просьбе запрашивающей Стороны ее процессуальных норм при оказании помощи учреждением запрашивающей Стороны.

Но в связи с этим необходимо принять во внимание один момент. Международное частноправовое законодательство государств хоть и не запрещает применение иностранных публично-правовых норм, но исключает применение иностранных правовых норм, закрепив такие институты, как оговорка о публичном порядке и императивная норма [21]. Согласно ст. 7 Римской Конвенции «О праве, применимом к договорным обязательства» от 1980 г. [33], ст. 5 Закона о МЧП, императивные нормы по причине обладания специальным назначением применяются независимо от права, применимого на основании этого Закона. Такие материально-правовые нормы специального назначения закреплены в Законе АР о Патенте от 1997 г. [35]. Например, положение «изобретение, полезная модель и промышленный образец, использование которых в коммерческих целях противоречит общественным интересам, принципам гуманизма и морали, наносят серьезный вред здоровью и жизни людей, животных, защите растений, окружающей среде, не охраняются патентом, и их использование запрещено» в ст. 3 Закона о Патенте является материально-правовой нормой императивного характера.

Согласно изложенному можно прийти к такому предварительному выводу:

1) возможно возникновение правовой коллизии в связи с международно-правовой защитой патентных прав;

2) в международно-правовой защите патентных прав может быть использован метод как прямого, так и непрямого (коллизионно-правового) регулирования;

3) наличие обобщенных материально-правовых норм специального назначения, касающихся международно-правовой защиты патентных прав, исключает коллизионно-правовое регулирование.

Как отметили в начале, одним из главных особенностей регулирования международно-правовой защиты патентных прав в рамках международного частного права является обеспечение согласования международного и национального правового регулирования, так как устранение территориального характера патентных прав и их международно-правовая защита невозможна без наличия средств международного регулирования. Конечно, среди этих средств международные договоры занимают особое место. Но это отнюдь не исключает использование в регулировании международных обычаев других правовых средств, принятых международными организациями актов. Так, профессор М.М. Богуславский отмечает наличие трех правовых основ устранения территориальной проблемы в области авторского права [4, с. 18-19]:

1) многосторонние международные договоры;

2) двусторонние международные договоры;

3) принцип взаимности.

К слову, выступление международных договоров и принципа взаимности в качестве правовой основы также закреплено в Законе о Патенте. А в качестве примера использования актов, принятых международными организациями, в правовом регулировании можно привести ту же самую законодательную практику Европейского Союза (Рим II). В направлении согласования международно-правового и национально-правового регулирования необходимо учитывать два свойства. Во-первых, международно-правовая защита патентных прав, соответственно, наряду с наличием необходимых для этого процессуальных форм также обуславливает взаимосвязь международных и внутригосударственных форм защиты. Как отмечалось, такая связь осуществляется в рамках международного гражданского процесса как составляющая международного частного права. Взаимодействие внутригосударственных и международных механизмов защиты, входящих в правовое содержание международно-гражданского процесса, основывается на необходимость решения единой задачи - защиты гражданских прав частных лиц на фоне не нарушения публичного порядка [9, с. 141]. Осуществление взаимодействия в международно-правовой защите патентных прав основывается на неизменном принципе. Согласно такому принципу, действие международных механизмов защиты начинается после неэффективного завершения действия внутригосударственных механизмов.

Во-вторых, международно-правовая защита патентных прав происходит фактически в пределах национальной правовой системы. В действительности комплексность международно-частного правового регулирования также должна быть объяснена именно этим, формулировкой содержания международного характера в национальной форме [20, с. 24]. Так, Европейская Патентная Конвенция (ст. 64 (3)), устанавливающая условия предоставления патента, патентные права, закрепляет рассмотрение любого нарушения 
патента в соответствии с национальным законодательством. В то же время в ст. 2 (п. 1) Парижской Конвенции определена возможность пользования гражданами государства, являющегося членом Союза, на территории другого члена Союза средствами правовой защиты, предусмотренными для его граждан. При этом положения национального законодательства государств-членов, относящиеся к судебной и административной процедуре и к полномочиям судебных и административных органов, должны быть соблюдены беспрекословно (п. 3).

Исходя из изложенных особенностей, можно прийти к двум выводам:

1) международно-правовая защита патентных прав составляет предмет совместного регулирования международного права и национального права;

2) такое регулирование осуществляется в форме взаимных отсылок к международным и национальным правовым нормам.

Выводы. Таким образом, международно-правовая защита патентных прав, будучи институтом международного интеллектуального права, входит в систему международного частного права. C точки зрения правовой природы такой институт может иметь комплексный характер. Комплексный характер, в первую очередь, вытекает из своеобразных особенностей патентных прав. Комплексность названого правового регулирования выражается и в параллельном использовании материальных, процессуальных и коллизионных норм, касающихся международного и национального по происхождению права. С точки зрения эффективного правового регулирования используется как прямой, так и непрямой (отсылочный) метод регулирования.

Вместе с тем по-прежнему остаются некоторые проблемы в правовом регулировании (например, отсутствие соответствующих коллизионных норм; не проработанность санкций за нарушение ряда положений Патентного закона АР; отсутствие в гражданском законодательстве детального регулирования договоров о передаче исключительного права (уступке патента) и лицензионных договоров и так далее).

\section{Лuтература}

1. Аллахвердиев С.С. Курс международного частного (гражданского) права Азербайджанской Республики : Учебник. Баку, 2007. 390 с. (на азерб. языке).

2. Ануфриева Л.П. Международное частное право : В 3-х т. Том 1. Общая часть : Учебник. Москва : Изд-во БЕК, 2000. 288 с.

3. Богуславский М.M. Международное частное право. Москва : Изд. НОРМА, 2016. 672 с.

4. Богуславский М.M. Вопросы авторского права в международных отношениях. Москва : Наука, 1973. $334 \mathrm{c}$.
5. Вельяминов Г.М. Международное экономическое право и процесс. (Академический курс) : Учебник. Москва : Волтерс Клувер, 2004. 496 с.

6. Винковский В.И. Совершенствование механизма преодоления конфликта прав заявителей при подаче заявок на выдачу патента. Исторические, философские, политические и юридические науки, культурология и искусствоведение. Вопросы теории и практики. Тамбов : Грамота, 2014. № 6 (44) : в 2-х ч. Ч. I. C. $41-43$.

7. Гаджизаде Ф.Н. Международно-правовые и частноправовые аспекты охраны прав интеллектуальной собственности : автореф. дисс. ... канд. юрид. наук. Баку, 2004. 26 c.

8. Гетьман-Павлова И.В. Международное частное право : учебник. Москва : Изд. Эксмо, 2014. 752 с.

9. Дамиров И.З. Взаимодействие международного частного права и международного гражданского процесса : дисс. ... д-ра фил. по праву. Баку, 2014.186 с. (на азерб. языке).

10. ЕрпылеваН.Ю. Международное частное право : учебник. Москва : Изд. Юрайт, 2011. 1308 с.

11. Канашевский В.А. Международное частное право : Учебник. Москва : Международные отношения, $2006.698 \mathrm{c}$.

12. Керимов Г.Г. Правовая охрана объектов промышленной собственности в международном частном праве : автореф. дисс. ... канд. юрид. наук : 12.00.03. Баку, 2008. 21 c.

13. Крупко С.И. Коллизионно-правовые аспекты регулирования интеллектуальной собственности. Москва : Хозяйство и право, 2014. 64 с.

14. Крупко С.И. Деликтные обязательства в сфере интеллектуальной собственности в международном частном праве : Монография. Москва : Статут, 2018. 279 c.

15. Курс международного (публичного) права : В 2 т-х. II том. Особенная часть. Учебник / под об. ред. Э.А. Алиева. Баку : издат.-полиграфическое предприятие Гюняш-Б, 2018. 704 с. (на азерб. языке).

16. Лунц Л.А. Курс международного частного права : в 3 т. Москва : Спарк, 2002. 1007 с.

17. Мамедов А.Г. Закон о международном частном праве и проблема кодификация международного частного права в Азербайджанской Республике. Азербайджанский юридический журнал. 2002. № 1. С. 105-117 (на азерб. языке).

18. Мамедов А.Г. Законодательство Азербайджанской Республики о международном частном праве и международное право : автореф. дисс. ... канд. юрид. наук. Баку, 2005. 27 с. (на азерб. языке).

19. Мамедов А.Г. Общепризнанные принципы международного права как правовое основание законодательства Азербайджанской Республики о международном частном праве. Азербайджанский юридический журнал. Баку, 2004. № 3. С. 86-97 (на азерб. языке).

20. Махмудова О.А. Международное частноправовое регулирование отношений Турция - Азербайджан. Баку : Бакинский Дом Печати, 2013. 220 с. (на азерб. языке).

21. Международное частное право: Иностранное законодательство / Предисл. А.Л. Маковского ; сост. и науч. ред. А.Н. Жиильцов, А.И. Муранов. Москва : Статут, 2001. 892 с.

22. Международное частное право : Учебник / Л.П. Ануфриева, К.А. Бекяшев, Г.К. Дмитриева и др.; отв. ред. Г.К. Дмитриева. 2-е изд., перераб. и доп. Москва : ТК Велби, Изд-во Проспект, 2004. 688 с.

23. Международное частное право : Современные проблемы / Отв. ред. М.М. Богуславский. Москва : ТЕИС, 1994. $507 \mathrm{c.}$ 
24. Нешатаева Т.Н. Международное частное право и международный гражданский процесс : Учебный курс в трех частях. Москва : ОАО изд. дом Городец, 2004.624 c.

25. Толстых В.Л. Коллизионное регулирование в международном частном праве: проблемы токования и применения раздела VII части третьей ГК РФ. Москва : Спарк, 2002. 244 c.

26. Bagley M., Okediji R., Erstling J. International Patent Law and Policy (American Casebook Series). West, 2013. $960 \mathrm{p}$.

27. Malbon J., Lawson C., Davison M. WTO Agreement on Trade-Related Aspects of Intellectual Property Rights: A Commentary. International Review of Intellectual Property and Competition Law. 2015. No. 46. P. 999-1001.

28. Кафедра интеграционного и европейского права МГЮА. Тесты для МПИ. Веб-сайт. URL: https:/ /eulaw. edu.ru/2019/10/tests-mpi/\#more-1906 (дата обращения: 18.01.2021).

29. Факультет права НИУ ВШЭ. Веб-сайт. URL: pravo.hse.ru (дата обращения: 18.01.2021).

30. Ваш гід в законодавстві України. Вебсайт. URL: kodeksy.com.ua (дата обращения: 18.01.2021).

31. Turk Hukuk Sitesi. Веб-сайт. URL: turkhukuksitesi.com/mevzuat.php?kid=27 (дата обращения: 18.01.2021).

32. Факультет права НИУ ВШЭ. Веб-сайт. URL: pravo.hse.ru/intprilaw/doc/041701 (дата обращения: 18.01.2021).

33. O международном частном праве : Закон Азербайджанской Республики от 6 июня 2000 года № 889-IQ. Континент : веб-сайт. URL: http:// continent-online.com/Document/?doc_id=30609267 (дата обращения: 18.01.2021).

34. О патенте : Закон Азербайджанской Республики от 25 июля 1997 года № 312-1Г. WIPO : веб-сайт. URL: https://www.wipo.int/edocs/lexdocs/laws/ru/az/ az010ru.pdf (дата обращения: 18.01.2021).

35. Парижская конвенция по охране промышленной собственности. WIPO : веб-сайт. URL: https:// www.wipo.int/edocs/lexdocs/treaties/ru/paris/trt paris 001ru (дата обращения: 18.01.2021).

$3 \overline{6}$. Малбон Дж., Лоусон Ч., Дэвисон М. Соглашение ВТО по торговле - Сопутствующие аспекты права интеллектуальной собственности. SpringerLink : вебсайт. URL: https://link.springer.com/article/10.1007/ s40319-015-0416-у (дата обращения: 18.01.2021).

\section{Аннотация}

Мамедова Нигяр И. Особенности правового регулирования международной защиты патентных прав. - Статья.

В статье рассматривается юридическая природа прав на результаты интеллектуальной деятельности и уясняется их место в системе права, характер и содержание этих прав. По мере дальнейшего развития научно-технического прогресса появляются новые объекты промышленной собственности, требующие новых способов правового регулирования и общего совершенствования законодательства, связанного с признанием и охраной прав интеллектуальной собственности как на национальном, так и на международном уровне. Так как патентные права имеют территориальный характер, обеспечить их международно-правовую защиту лишь национальным правом невозможно. В международно-правовой защите патентных прав международные и национальные правовые нормы участвуют параллельно. Излагая одну и ту же волю, эти нормы, выраженные в различных формах, составляют правовую основу режима целостности защиты патентных прав. Специальные коллизионные и юрисдикционные правила для интеллектуальной собственности еще только начинают складываться. Территориальность интеллектуальной собственности значительно ограничивает применение коллизионных норм, а также правил международного гражданского процесса и международного коммерческого арбитража к отношениям интеллектуальной собственности с иностранным элементом. Преимущественно работы по вопросам международной охраны интеллектуальной собственности сводятся к характеристике основных международных договоров в этой области. Реалий современного времени международно-правового метода регулирования, выражающегося в заключении международных договоров по вопросам интеллектуальной собственности, уже недостаточно, необходимо решать задачи международной охраны интеллектуальной собственности с помощью традиционных механизмов международного частного права. Либерализация международной торговли товарами и услугами, воплощающими объекты интеллектуальной собственности, а также развитие информационно-цифровых технологий, облегчающих доступ к объектам интеллектуальной собственности из любой точки мира, заставляют примерять конструкции международного частного права к отношениям интеллектуальной собственности с иностранным элементом.

Ключевые слова: личные патентные права, территориальный характер патентных прав, международные договора, международно-правовая защита патентных прав, коллизионное правовое регулирование.

\section{Анотація}

\section{Маледова Нігяр I. Особливості правового} регулювання міжнародного захисту патентних прав. - Стаття.

У статті розглядається юридична природа прав на результати інтелектуальної діяльності й з'ясовується їх місце в системі права, характер і зміст таких прав. 3 подальшим розвитком науково-технічного прогресу з'являються нові об'єкти промислової власності, що вимагають нових способів правового регулювання та загального вдосконалення законодавства, пов'язаного з визнанням та охороною прав інтелектуальної власності як на національному, так і на міжнародному рівні. Оскільки патентні права мають територіальний характер, забезпечити їх міжнародно-правовий захист лише національним правом неможливо. У міжнародно-правовому захисті патентних прав міжнародні й національні правові норми беруть участь паралельно. Висловлюючи одну й ту ж волю, норми, виражені в різних формах, становлять правову основу режиму цілісності захисту патентних прав. Спеціальні колізійні та юрисдикційні правила для інтелектуальної власності ще тільки починають складатися. Територіальність інтелектуальної власності значно обмежує застосування колізійних норм, а також правил міжнародного цивільного процесу й міжнародного комерційного арбітражу до відносин інтелектуальної власності з іноземним елементом. Переважно роботи з питань міжнародної охорони інтелектуальної власності зводяться до характеристики основних міжнародних договорів у цій галузі. Реалій сучасного часу міжнародно-правового методу регулювання, що виражається в укладенні міжнародних договорів із питань інтелектуальної власності, вже 
не досить, необхідно розв'язувати завдання міжнародної охорони інтелектуальної власності за допомогою традиційних механізмів міжнародного приватного права. Лібералізація міжнародної торгівлі товарами й послугами, що втілюють об'єкти інтелектуальної власності, а також розвиток інформаційно-цифрових технологій, який полегшує доступ до об'єктів інтелектуальної власності з будь-якої точки світу, змушують приміряти конструкції міжнародного приватного права до відносин інтелектуальної власності з іноземним елементом.

Ключові слова: особисті патентні права, територіальний характер патентних прав, міжнародні договори, міжнародно-правовий захист патентних прав, колізійне правове регулювання.

\section{Summary}

Mammadova Nigar I. Features of legal regulation of international protection of patent rights. - Article.

The article examines the legal nature of rights to the results of intellectual activity and clarification of their place in the system of law, the nature and content of these rights. With the further development of scientific and technological progress, new objects of industrial property appear, requiring new methods of legal regulation and general improvement of legislation related to the recognition and protection of intellectual property rights, both at the national and international levels. Patent rights are territorial in nature, it is impossible to ensure their international legal protection only by national law. The regulation of patent protection is complex. The complex nature arises from the peculiar features of patent rights.
The complexity of legal regulation is expressed in the parallel use of substantive, procedural and conflict-of-law rules concerning international and national law in origin. In international legal protection of patent rights, international and national legal norms are involved in parallel. Expressing the same will, these norms, expressed in different forms, constitute the legal basis of the integrity regime for the protection of patent rights. Special conflict and jurisdictional rules for intellectual property are just beginning to emerge. The territoriality of intellectual property significantly limits the application of conflict of laws, as well as the rules of international civil procedure and international commercial arbitration to the relationship of intellectual property with a foreign element. Mostly works on international protection of intellectual property is reduced to the characteristics of the main international treaties in this area. The reality of nowadays, the international legal methods of regulation, expressed in the conclusion of international treaties on intellectual property, is no longer enough, it is necessary to solve the problems of international protection of intellectual property with the help of traditional mechanisms of international private law. The liberalization of international trade in goods and services that embody intellectual property objects, as well as the development of information and digital technologies that facilitate access to intellectual property from everywhere in the world, force us to try the constructions of private international law on the relationship of intellectual property with a foreign element.

Key words: personal patent rights, territorial nature of patent rights, international agreements, international legal protection of patent rights, conflict of law regulation. 